\title{
O NCPC E A "FUNGIBILIDADE" DOS RECURSOS ESPECIAL E EXTRAORDINÁRIO
}

Vinicius Jucá Alves

\section{INTRODUÇÃO}

O Novo Código de Processo Civil (NCPC), introduzido pela Lei n 13.105/2015, tem a característica de privilegiar o direito material sobre as formalidades processuais, isto é, preferir a resolução da questão de mérito ao encerramento do processo por questões formais. Nesse sentido, o art. $4^{\circ}$ do NCPC é expresso: “As partes têm o direito de obter em prazo razoável a solução integral do mérito, inclú́da a atividade satisfativa". A doutrina tem chamado essa característica de "princípio da primazia da resolução do mérito". Um exemplo emblemático dessa orientação é o art. 282, \ 20: "Quando puder decidir o mérito a favor da parte a quem aproveite a decretação da nulidade, o juiz não a pronunciará nem mandará repetir o ato ou suprir-lhe a falta".

E essa orientação também pode ser observada no Recurso Especial (REsp) e no Recurso Extraordinário (RE), que são objeto do presente estudo. Os art. 1.032 e 1.033 do NCPC preveem a possibilidade de aproveitamento do RE que discute ofensa reflexa à Constituição (por meio do seu julgamento como REsp), bem como do REsp que verse sobre questão constitucional (por meio do seu julgamento como RE):

Art. 1.032. Se o relator, no Superior Tribunal de Justiça, entender que o recurso especial versa sobre questão constitucional, deverá conceder prazo 
de 15 (quinze) dias para que o recorrente demonstre a existência de repercussão geral e se manifeste sobre a questão constitucional.

Parágrafo único. Cumprida a diligência de que trata o caput, o relator remeterá o recurso ao Supremo Tribunal Federal, que, em juízo de admissibilidade, poderá devolvê-lo ao Superior Tribunal de Justiça.

Art. 1.033. Se o Supremo Tribunal Federal considerar como reflexa a ofensa à Constituição afirmada no recurso extraordinário, por pressupor a revisão da interpretação de lei federal ou de tratado, remetê-lo-á ao Superior Tribunal de Justiça para julgamento como recurso especial.

Sem dúvida estamos diante de valioso mecanismo, que assegura à parte a apreciação de questões relevantes por meio dos apelos extremos ao Superior Tribunal de Justiça (STJ) e ao Supremo Tribunal Federal (STF).

\section{OS ART. 1.032 E 1.033 TRATAM DE FUNGIBILIDADE RECURSAL?}

Inicialmente, vale a reflexão sobre a natureza jurídica dos comandos trazidos pelos art. 1.032 e 1.033 do NCPC. Eles tratam de fungibilidade recursal?

O princípio da fungibilidade recursal, de forma genérica, não estava expresso no Código de Processo Civil de 1973 (CPC/73) nem está no NCPC, mas já esteve no Código de Processo Civil de 1939, por exemplo: “Art. 810. Salvo a hipótese de má-fé ou erro grosseiro, a parte não será prejudicada pela interposição de um recurso por outro, devendo os autos ser enviados à Câmara, ou turma, a que competir o julgamento." Apesar disso, a doutrina e a jurisprudência consagraram que esse princípio continuaria sendo cogente. Com mais razão, entendemos que a fungibilidade recursal deve ser aplicada no NCPC, que, como vimos, privilegia a instrumentalidade das formas e a resolução do mérito das controvérsias.

Sobre a aplicação da fungibilidade recursal no CPC/73, confira-se a lição de Misael Montenegro Filho: ${ }^{1}$

A instrumentalidade das formas também é realidade na matéria recursal, importando na possibilidade de um recurso ser conhecido - vale dizer, processado - quando um outro seria o cabível. É com apoio nessa premissa

1 MONTENEGRO FILHO, Misael. Curso de direito processual civil. São Paulo: Atlas, 2005. p. 54. v. 2. 
básica que a doutrina vem admitindo a aplicação da fungibilidade na matéria recursal [...].

Contudo, para a aplicação do princípio na matéria recursal, deve a parte preencher dois requisitos cumulativos (e não alternativos), a saber:

a) Interpor o recurso equivocado no prazo correto;

b) Afastar a alegação de que teria ocorrido erro grosseiro, com a demonstração da denominada dúvida objetiva, e não a dúvida subjetiva, apenas existente no raciocínio do recorrente, sem nenhum apoio doutrinário e/ ou jurisprudencial. (grifo nosso)

No mesmo sentido, a lição do Ministro Luiz Fux:²

A influência do princípio da instrumentalidade das formas, no campo da inadequação procedimental, reascendeu a aplicação do vetusto princípio da fungibilidade dos recursos, cuja incidência permite o aproveitamento do recurso interposto como se fosse o meio de impugnação cabível e não utilizado. Fundando-se em ordenação pretérita, a jurisprudência consagrou essa possibilidade, desde que ausente erro grosseiro e a má fé do recorrente. Um dos critérios utilizados tem sido a escorreita verificação da tempestividade, por isso, um recurso de prazo menor é aceito se interposto no lugar daquele cabível cujo prazo de oferecimento é mais alongado. (grifo nosso)

Ainda sobre os requisitos para que seja aplicada a fungibilidade recursal, confira-se trecho de decisão do STJ: “(i) caracterização de dúvida objetiva a respeito da medida impugnativa a ser manejada, o que é suficiente para afastar eventual configuração de erro grosseiro, e (ii) observância do prazo para o protocolo efetivamente cabível" (Recurso Ordinário em Mandado de Segurança n. 31.840, Rel. Min. Mauro Campbell Marques, $2^{\text {a }}$ Turma, publicado em: 12 nov. 2010, grifo nosso). Como descrito, a aplicação da fungibilidade recursal depende de um requisito de avaliação subjetiva, a cargo do julgador: a constatação de que a parte não cometeu erro grosseiro na interposição do recurso que se pretende aproveitar. Por esse motivo, entendemos que os art. 1.032 e 1.033 do NCPC não tratam de fungibilidade recursal.

2 FUX, Luiz. Curso de Direito Processual Civil. 4. ed. Rio de Janeiro: Forense, 2008. p. 730. v. 1. 
Os referidos artigos não impõem a existência de dúvida objetiva, ou a ausência de erro grosseiro. Em tese, o RE pode tratar claramente de ofensa reflexa à Constituição e, mesmo assim, o NCPC determina que o STF o envie para julgamento pelo STJ. Da mesma forma, o REsp pode tratar claramente de ofensa à Constituição, mas o NCPC determina que o relator no STJ abra prazo para a parte demonstrar a repercussão geral e envie o recurso para julgamento pelo STF.

Ora, quando o NCPC pretendeu atribuir essa avaliação subjetiva ao STF e ao STJ, ele o fez expressamente, conforme se pode notar da transcrição do $\int 3^{\circ}$ do art. 1.029: “O Supremo Tribunal Federal ou o Superior Tribunal de Justiça poderá desconsiderar vício formal de recurso tempestivo ou determinar sua correção, desde que não o repute grave" (grifo nosso).

Então, podemos concluir que os art. 1.032 e 1.033 não tratam de fungibilidade recursal, pois o NCPC não atribui ao relator no STJ ou à turma (ou plenário) no STF a avaliação da existência de dúvida objetiva ou erro grosseiro na interposição dos recursos. Uma vez constatada uma das hipóteses dos art. 1.032 e 1.033, eles devem ser aplicados, aproveitando-se o recurso da parte, para que o mérito seja resolvido pelo STJ ou pelo STF. Aqui, mais uma vez, aplica-se o "princípio da primazia da resolução do mérito". A parte não deixará de ter o mérito da sua questão analisado por uma situação de quase "conflito negativo" entre STF e STJ.

No passado, era possível vislumbrar a situação extrema da parte que interpunha REsp e RE, mas tinha seu REsp não analisado pelo STJ, por este considerar que a questão discutida era constitucional, e seu RE não analisado pelo STF, por este considerar que a questão envolvia ofensa reflexa à Constituição. Com os art. 1.032 e 1.033, a tendência é que isso não ocorra mais, pois o STF pode, em última instância, determinar que a questão será revista pelo STJ.

A aplicação desses dispositivos deverá ser objeto de regulamentação pelo STJ e pelo STF em seus respectivos regimentos internos. De qualquer forma, analisaremos adiante algumas mudanças que podemos esperar em decorrência dos art. 1.032 e 1.033.

\section{ART. 1.032 - O RESP NO STJ}

Como já indicamos, de acordo com o art. 1.032, sempre que verificar que o REsp trata de matéria constitucional, o relator no STJ abrirá prazo para que a parte demonstre a repercussão geral e se manifeste sobre a questão constitucional. $\mathrm{Ou}$ seja, esse prazo funciona como uma forma de aditamento do REsp para "transformá-lo” em RE. 
O Regimento Interno do STJ já foi alterado para prever esse instituto. O art. 21-E, inciso IX, prevê que também caberá ao presidente do STJ adotar a medida de remeter ao STF quando verificar, antes da distribuição, que o REsp trata de matéria constitucional. O art. 34, inciso XXIII, do mesmo Regimento Interno trata da providência adotada pelo relator quando a verificação ocorre depois da distribuição. Superada essa questão, o relator ou o presidente do STJ enviará o recurso ao STF. Por sua vez, o STF pode entender que se trata de ofensa reflexa e, nesse caso, enviará o recurso de volta para o STJ, que deverá julgar o mérito da ofensa a lei federal ou tratado.

Como já dissemos, trata-se de instituto novo que terá papel fundamental em evitar um "vazio de prestação jurisdicional". É razoável esperar que os detalhes do seu processamento sejam definidos pelo regimento interno dos tribunais superiores, mas certamente questões surgirão e serão dirimidas pela jurisprudência. No presente artigo, abordaremos dois pontos de questionamento desse novo instituto: (i) o art. 1.032 do NCPC é aplicável a REsp interpostos antes da vigência do NCPC?; e (ii) cabe agravo contra a decisão do relator do STJ que determina a providência do art. 1.032 do NCPC?

Sobre o primeiro ponto, vale lembrar que, em sessão realizada em 9 de março de 2016, o plenário do STJ editou o Enunciado Administrativo n. 2, transcrito a seguir:

\section{Enunciado Administrativo n. 2}

Aos recursos interpostos com fundamento no CPC/1973 (relativos a decisões publicadas até 17 de março de 2016) devem ser exigidos os requisitos de admissibilidade na forma nele prevista, com as interpretações dadas, até então, pela jurisprudência do Superior Tribunal de Justiça.

Portanto, o art. 1.032 do NCPC somente será aplicado aos REsp interpostos antes de 17 de março de 2016, data de vigência do NCPC, se pudermos concluir que esse dispositivo não trata de requisitos de admissibilidade dos REsp.

Até o advento do NCPC, era comum que os REsp que versassem sobre matéria constitucional não fossem admitidos pelo STJ. Sob esse ponto de vista, seria possível alegar que o art. 1.032 do NCPC trata de admissibilidade e, portanto, tal dispositivo somente deveria ser aplicado para REsp interpostos depois de 17 de março de 2016. Antes, os REsp não eram admitidos se tratassem de matéria constitucional, mas agora o art. 1.032 do NCPC remedia essa situação autorizando a emenda do recurso e a sua remessa ao STF. Discordamos dessa argumentação. 
A nosso ver, o art. 1.032 do NCPC deveria ser aplicado imediatamente inclusive aos REsp interpostos antes de 17 de março de 2016, uma vez que esse dispositivo não alterou os requisitos de admissibilidade do REsp. Esse comando legal não determina que o relator do STJ receba e processe o REsp que trata de matéria constitucional, mas que o relator abra prazo para a parte emendar o recurso e, posteriormente, envie o recurso ao STF para ser processado como RE, não REsp.

O segundo ponto diz respeito à possibilidade de interpor agravo interno contra a decisão do relator no STJ que aplica o art. 1.032. O art. 1.021 do NCPC possibilita a interposição de agravo interno de forma genérica contra decisões proferidas pelo relator. Como dissemos, o Regimento Interno do STJ já foi atualizado para contemplar esse instituto e prevê o agravo. Caso a decisão seja tomada pelo presidente do STJ, então o agravo está previsto no art. 21-E, $\ 2^{\circ}$. Caso seja tomada pelo relator, o agravo está previsto no art. 259.

\section{ART. 1.033 - O RE NO STF}

$\mathrm{O}$ art. 1.033 estabelece que o STF, caso identifique que o RE trata de ofensa reflexa à Constituição, enviará esse recurso para ser julgado pelo STJ como REsp. Diferente do art. 1.032, o art. 1.033 não estabelece que providência caberá ao relator do RE no STF. Assim, é possível inferir que a providência do art. 1.033 caberá ao colegiado.

Caso essa conclusão se confirme, seja por inclusão de previsão no Regimento Interno do STF, seja pela jurisprudência, então não haverá discussão sobre o cabimento do agravo interno. Isso porque se a providência for adotada pelo colegiado, não cabe o agravo interno previsto no art. 1.021 do NCPC.

Um ponto que chama atenção é a situação em que a parte interpõe REsp e RE e o STJ julga improcedente o REsp no mérito, por entender que não houve ofensa a lei federal ou tratado. Posteriormente, caso o STF identifique que o RE trata de ofensa reflexa, resta saber se deveria aplicar o art. 1.033 e enviar o RE para ser julgado pelo STJ como REsp, mesmo já havendo decisão do STJ no mérito determinando que tal ofensa a lei federal ou a tratado não existe. Essa situação também não está prevista no NCPC e deve ser objeto dos Regimentos Internos do STF e do STJ.

\section{A SÚMULA N. 126 DO STJ PERMANECE VÁLIDA?}

Com o regime criado pelos art. 1.032 e 1.033 do NCPC, surge a questão sobre a aplicabilidade da Súmula n. 126 do STJ, editada em 9 de março de 1995 com a 
seguinte redação: "É inadmissível recurso especial, quando o acórdão recorrido assenta em fundamentos constitucional e infraconstitucional, qualquer deles suficiente, por si só, para mantê-lo, e a parte não manifesta recurso extraordinário".

A princípio, entendemos que a Súmula n. 126 do STJ permanece válida, pois trata de situação diferente daquelas reguladas pelos art. 1.032 e 1.033 do NCPC. Como já discutimos, o objetivo dos referidos artigos é evitar um vazio na prestação jurisdicional, principalmente na situação em que o STJ não analisa a demanda da parte por entender que se trata de uma discussão constitucional, e o STF também não o faz por entender que a discussão trata de ofensa reflexa à Constituição.

Contudo, a Súmula n. 126 do STJ versa sobre situação em que o acórdão recorrido tem por base fundamentos legal e constitucional, qualquer deles suficiente para manter a decisão. Nesse caso, a parte ainda deve apresentar REsp e RE; os art. 1.032 e 1.033 não afastam essa necessidade. Sem dúvida, se a parte interpuser os dois recursos e o STJ entender que o REsp trata de discussão constitucional, então não aplicará a Súmula n. 126, mas o art. 1.032, e enviará o recurso ao STF.

Por outro lado, se a parte interpuser os dois recursos e o STJ entender que o REsp é cabível, então o julgará e enviará o RE para o STF. Se o STF entender que o RE não é cabível, por tratar de ofensa reflexa, então o enviará para o STJ (observadas as nossas considerações do item anterior). Mas se a parte não interpuser o REsp e o RE e o STJ entender que deveria ser interposto RE contra questão constitucional que sustenta o acórdão recorrido, então o STJ ainda pode aplicar a Súmula n. 126 e não admitir o REsp.

\section{CONSIDERAÇÕES FINAIS}

Diante do exposto, podemos concluir que:

i. Os art. 1.032 e 1.033 são mecanismos de extrema importância, pois criam um regime que evita o vazio jurisdicional, principalmente na situação em que o STJ não analisa a demanda da parte por entender que se trata de uma discussão constitucional, e o STF também não o faz por entender que a discussão trata de ofensa reflexa à Constituição.

ii. Os artigos 1.032 e 1.033 não tratam de fungibilidade recursal, pois o NCPC não atribui ao relator no STJ ou à turma (ou plenário) no STF a avaliação sobre a existência de dúvida objetiva ou erro grosseiro na interposição dos recursos. Uma vez constatada uma das hipóteses dos art. 1.032 e 1.033, eles devem ser aplicados, aproveitando-se o recurso da parte, para que o mérito seja resolvido pelo STJ ou pelo STF. 
iii. Nos termos do art. 1.032 do NCPC, sempre que verificar que o REsp trata de matéria constitucional, o relator no STJ abrirá prazo para que a parte demonstre a repercussão geral e se manifeste sobre a questão constitucional.

iv. Nos termos do parágrafo único do art. 1.032 do NCPC, o STF pode entender que o recurso enviado pelo STJ com base no caput trata de ofensa reflexa à Constituição e, nesse caso, enviará o recurso de volta para o STJ, que deverá julgar o mérito da ofensa a lei federal ou tratado.

v. O art. 1.032 deve ser aplicado para REsp interpostos antes e depois da entrada em vigência do NCPC (17 de março de 2016), não se aplicando o Enunciado Administrativo n. 2 do plenário do STJ a esse dispositivo.

vi. Cabe agravo interno (art. 1.021 do NCPC) contra a decisão do presidente ou relator no STJ que aplica o art. 1.032.

vii. $\mathrm{O}$ art. 1.033 estabelece que o STF, caso identifique que o RE trata de ofensa reflexa à Constituição, enviará esse recurso para ser julgado pelo STJ como REsp. A princípio, é possível entender que essa determinação cabe ao colegiado do STF.

viii. Os art. 1.032 e 1.033 não afastam a aplicação da Súmula n. 126 do STJ. 